\title{
Hippocampal and amygdaloid interactions in the nucleus accumbens
}

\author{
HENK J. GROENEWEGEN \\ Vrije Universiteit, Amsterdam, The Netherlands \\ ANTONIUS B. MULDER \\ University of Amsterdam, Amsterdam, The Netherlands \\ ARNO V. J. BEIJER and CHRISTOPHER I. WRIGHT \\ Vrije Universiteit, Amsterdam, The Netherlands \\ FERNANDO H. LOPES DA SILVA \\ University of Amsterdam, Amsterdam, The Netherlands \\ and \\ CYRIEL M. A. PENNARTZ \\ Netherlands Institute for Brain Research, Amsterdam, The Netherlands
}

\begin{abstract}
The nucleus accumbens, in view of its afferent and efferent fiber connections, appears to hold a key position for "limbic" (e.g., hippocampal and amygdaloid) influences to reach somatomotor and autonomic brain structures, and it has therefore been considered as a limbic-motor interface. The nucleus accumbens can be subdivided into a shell and a core region, which both contain further inhomogeneities. The present account first summarizes the detailed topographical anatomical relationships of inputs from different dorso-ventral parts of the hippocampus and different rostrocaudal parts of the basal amygdaloid complex at the level of the accumbens. Subsequently, the electrophysiological characteristics of hippocampal and amygdaloid inputs in the accumbens are described. Interactions between hippocampal and amygdaloid inputs appear to exist primarily in the medial parts of both the shell and the core of the nucleus accumbens. In the short term, stimulating amygdaloid inputs appear to facilitate hippocampal throughput (heterosynaptic paired pulse facilitation), whereas stimulation of hippocampal inputs depresses amygdaloid throughput in a paired pulse paradigm. Tetanic stimulation of hippocampal inputs to the accumbens leads to a decremental long-term potentiation (LTP) of this fiber pathway (homosynaptic LTP) but, along a similar time range, to a depression of amygdaloid inputs (heterosynaptic long-term depression). The involvement of dopaminergic, GABAergic, and glutamatergic mechanisms in these interactions is discussed. Finally, it is suggested that the interactions between hippocampal and amygdaloid inputs at the level of the nucleus accumbens play a role in different aspects of associative learning.
\end{abstract}

The nucleus accumbens (Acb) is a brain area located in the rostroventral part of the basal forebrain. Following the seminal paper by Heimer and Wilson in 1975, the Acb has been considered a component of the so-called ventral

The authors wish to thank Wil J. A. J. Smeets for his critical comments on the paper, Martijne Mendes-de Leon and Jolinda Kos for secretarial assistance, and Dirk de Jong for his photographic contribution. A.B.M. was in the Institute for Neurobiology at the University of Amsterdam at the time of this research; he is now at the Netherlands Institute for Brain Research. A.V.J.B. is in the Research Institute Neurosciences, Department of Anatomy at the Vrije Universiteit, as was C.I.W. when this research was done; C.I.W. is now at the Department of Neurology, Harvard Medical School, Brigham and Women's Hospital, Boston. F.H.L.S. is in the Institute for Neurobiology at the University of Amsterdam. Correspondence should be addressed to H. J. Groenewegen, Department of Anatomy, Faculty of Medicine, Vrije Universiteit, Van der Boechorststraat 7, 1081 BT Amsterdam, the Netherlands (e-mail: hj.groenewegen.anat@med.vu.nl). striatum, which further includes the ventromedial parts of the caudate-putamen complex and the striatal elements of the olfactory tubercle. The ventral striatum in general, and the Acb in particular, is thought to be involved in various complex behavioral functions, including sensorimotor, motivational, and adaptational processes (Cador, Robbins, \& Everitt, 1989; Everitt, Morris, O'Brien, \& Robbins, 1991; Groenewegen, Berendse, Wolters, \& Lohman, 1990; Groenewegen, Wright, \& Beijer, 1996; Mogenson, Jones, \& Yim, 1980; Pennartz, Groenewegen, \& Lopes da Silva, 1994; Scheel-Krüger \& Willner, 1991; Zahm \& Brog, 1992). Further, the Acb plays a prominent role in reward learning, and this nucleus has been implicated in schizophrenia and other affective disorders, as well as in drug abuse (Koob, 1992; Robbins \& Everitt, 1996).

In terms of fiber connections, the Acb is characterized by strong inputs from limbic lobe-related structures, such as the hippocampal formation, basal amygdaloid complex, 
parahippocampal cortex, and anterior cingulate cortex. Other inputs are derived from the prefrontal cortex, the midline thalamic nuclei, the dopaminergic ventral tegmental area and the serotonergic median raphe nucleus (Brog, Salyapongse, Deutch, \& Zahm, 1993; Groenewegen, Becker, \& Lohman, 1980; Groenewegen, Room, Witter, \& Lohman, 1982; Groenewegen, Vermeulen-Van der Zee, te Kortschot, \& Witter, 1987; Kelley \& Domesick, 1982; Kelley, Domesick, \& Nauta, 1982; Newman \& Winans, 1980; Phillipson \& Griffiths, 1985; Totterdell \& Meredith, 1997). It projects, in turn, to various behavioral effector regions such as the ventral pallidum, the lateral hypothalamus, the ventral tegmental area, the substantia nigra pars compacta and caudal mesencephalic areas, including the so-called mesencephalic locomotor region, and adjacent, lateral parts of the central gray substance (Berendse, Groenewegen, \& Lohman, 1992; Heimer, Zahm, \& Alheid, 1995; Heimer, Zahm, Churchill, Kalivas, \& Wohltmann, 1991; Nauta, Smith, Faull, \& Domesick, 1978). The Acb appears to hold a key position in the pathways by which motivational and emotional influences reach somatomotor and autonomic brain structures. In this respect, the nucleus has been considered a limbic-motor interface (Groenewegen et al., 1996; Mogenson et al., 1980).

The Acb has long been treated as a homogeneous structure, but recently it has been recognized that the Acb consists of various subdivisions. Most notably, a peripherally located "shell" and a centrally located "core" region have been recognized (Voorn, Gerfen, \& Groenewegen, 1989; Záborszky et al., 1985; Zahm \& Brog, 1992). This bipartition of the nucleus is primarily based on the differential histochemical characteristics of the shell and core. Results of neuroanatomical tracing studies indicate that the various afferent systems of the Acb appear to be inhomogeneously distributed over the nucleus, forming an intricate pattern that to a certain degree is related to the shell-core subdivision. Likewise, populations of output neurons that project to the various targets of the Acb appear to be inhomogeneously distributed over the nucleus (Berendse et al., 1992; Groenewegen et al., 1996; Heimer et al., 1997; Herkenham, Moon-Edley, \& Stuart, 1984). Moreover, results of numerous pharmacological and behavioral studies have revealed that there are major functional differences between Acb shell and core (e.g., Deutch \& Cameron, 1992; Kelley, Smith-Roe, \& Holahan, 1997; Parkinson, Olmstead, Burns, Robbins, \& Everitt, 1999; Stratford \& Kelley, 1997; Weiner, Gal, Rawlins, \& Feldon, 1996).

One of the most distinguishing features of the Acb is that this part of the striatum receives the major input from the hippocampal formation (Groenewegen et al., 1982; Groenewegen et al., 1987; Kelley \& Domesick, 1982). Relatively minor projections have been described from ventral and dorsal parts of the hippocampal formation to the most ventral parts of the caudal half of the striatum, encompassing the interstitial nucleus of the posterior limb of the anterior commissure (IPAC) and the extreme caudal part of the caudate-putamen complex, respectively
(Groenewegen et al., 1987). Amygdalostriatal projections have a much more widespread distribution than the hippocampostriatal fibers and include extensive parts of the caudate-putamen complex (Kelley et al., 1982; Kita \& Kitai, 1990; Wright et al., 1996). However, the Acb is reached by almost all parts of the basal amygdaloid complex in a highly topographical way (Wright et al., 1996). Thus, the Acb is a main potential convergence site of hippocampal and amygdaloid influences on the basal ganglia and, through the output of these structures, on behavioral functions. The hippocampal formation and amygdala are thought to be involved in different aspects of certain behaviors. The amygdala, in forming stimulusreward and stimulus-punishment associations, serves as a link between sensory systems and structures involved in the expression of emotional behavior (Adolphs, Tranel, Damasio, \& Damasio, 1995; Davies, 1992; Everitt et al., 1991; LeDoux, 1993). The hippocampal formation is important for memory functions, particularly those involving spatial cues (Alvarez, Zola-Morgan, \& Squire, 1995; ZolaMorgan, Squire, Alvarez-Royo, \& Clower, 1991; ZolaMorgan, Squire, \& Amaral, 1986, 1989). Interestingly, manipulations of either the hippocampal or the amygdaloid systems, through the Acb, have led to different, and in some instances opposing, effects on behavior (e.g., locomotor activity; for a review, see Pennartz et al., 1994).

In view of the topographical organization of both the hippocampal and amygdaloid inputs to the Acb, the intrinsic heterogeneity of the nucleus, and the differential behavioral roles of the hippocampal formation and amygdala, the present paper provides a brief review of the anatomical and physiological relationships between these two limbic inputs at the level of the Acb. Unless otherwise specified, the descriptions below relate to data obtained in rats.

\section{ANATOMICAL RELATIONSHIPS BETWEEN HIPPOCAMPAL AND AMYGDALOID INPUTS IN THE NUCLEUS ACCUMBENS}

\section{Immunohistochemical and Cytoarchitectonic Framework of the Nucleus Accumbens}

The differential distribution of immunoreactivity for the calciumbinding protein Calbindin $\mathrm{D}_{28 \mathrm{~K}}(\mathrm{CaB})$ provides the generally accepted means of subdividing the Acb into a shell and a core region (Jongen-Rêlo, Voorn, \& Groenewegen, 1994; Zahm \& Brog, 1992; Figure 1). For the subsequent description of the termination patterns of hippocampal and amygdaloid inputs, as well as for the location of the recording electrodes in the Acb, we have used the pattern of immunoreactivity of $\mathrm{CaB}$ as a reference. In the following paragraph, a brief description of the Acb cytoarchitecture and the differential distribution of $\mathrm{CaB}$ immunoreactivity over the nucleus is given.

As shown in Figure 1, the centrally located core is in general strongly immunoreactive for $\mathrm{CaB}$, whereas the medially, ventrally, and, in part, laterally located shell has a much lower level of $\mathrm{CaB}$ immunoreactivity. $\mathrm{CaB}$ im- 

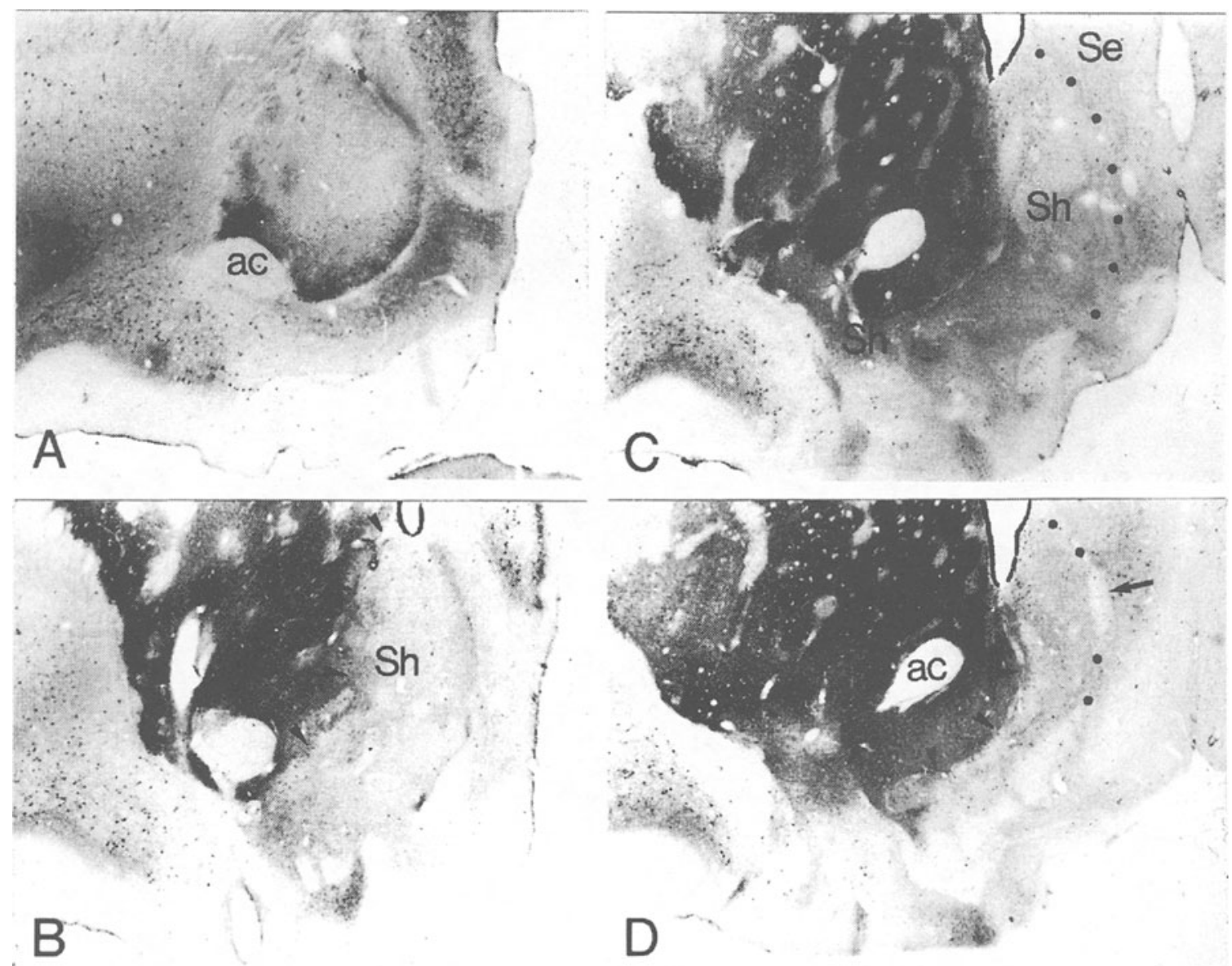

Figure 1. Photomicrographs of four transverse sections through the Acb, immunostained for CaB. A, rostral; D, caudal. Arrowheads in B-D indicate the border between shell (Sh) and core (C) of the Acb; small dots in $C$ and $D$ mark the border between the septal nuclei and the Acb. Note that the shell shows much less $\mathrm{CaB}$-immunoreactivity than the core but that the shell is inhomogeneous in itself, exhibiting moderate immunoreactivity in the lateral shell and almost no immunoreactivity for $\mathrm{CaB}$ in medial shell. The core contains patches of light or moderate levels of immunoreactivity for CaB. The rostral part of the Acb (A), with the exception of a lateral region, is lightly immunoreactive for $\mathrm{CaB}$ and has been included in the shell on the basis of this characteristic (Jongen-Rêlo, Voorn, \& Groenewegen, 1994). ac, anterior commissure; Se, septal nuclei.

munoreactivity is very low in the rostral part of the Acb (Figure 1A). The medial and ventral rim of the nucleus shows a higher level of $\mathrm{CaB}$-immunoreactivity, whereas its most ventrolateral part exhibits a high intensity of immunoreactivity for $\mathrm{CaB}$, comparable with that in the $\mathrm{Acb}$ core (Figure 1B-1D). The largest, CaB-poor, part of the rostral Acb has been included in the shell compartment by Jongen-Rêlo et al. (1994) on the basis that, as seen in horizontal sections (cf. Figure 4 in Jongen-Rêlo et al., 1994), this part of the nucleus is merely continuous with the more caudal parts of the CaB-poor shell (Figure 1B1C). Zahm and Heimer (1993) have shown that the rostral part of the Acb has efferent connectional characteristics of both the shell and the core subdivisions, and they proposed calling this part of the Acb the "rostral pole."

At more caudal levels (Figure 1B-1D), the CaB-poor shell first occupies the medial and ventral parts of the nucleus (Figure 1B) and extends further caudally into the lateral part of the Acb (Figure 1C, 1D). Although it can be stated in general terms that the shell exhibits low levels of $\mathrm{CaB}$-immunoreactivity and the core high levels of this protein, both subregions are heterogeneous with respect to this and many other neuroactive substances. Thus, in the caudal Acb the medial part of the shell is very low in $\mathrm{CaB}$ immunoreactivity with immunonegative areas, which coincide with cell clusters in Nissl-stained sections and an area containing $\mathrm{CaB}$-positive neurons in the dorsomedial shell (Herkenham et al., 1984; Wright \& Groenewegen, 1995). At the same levels, the ventral shell contains areas of moderate $\mathrm{CaB}$ immunoreactivity, whereas the lateral shell exhibits a more homogeneous distribution of moderate $\mathrm{CaB}$ immunoreactivity (Figure 1C, 1D). Within the Acb core, patches of moderate or low $\mathrm{CaB}$ immunoreactivity are present that are similar to those in the ventromedial parts of the caudate-putamen complex (Figure 1B-1D). 

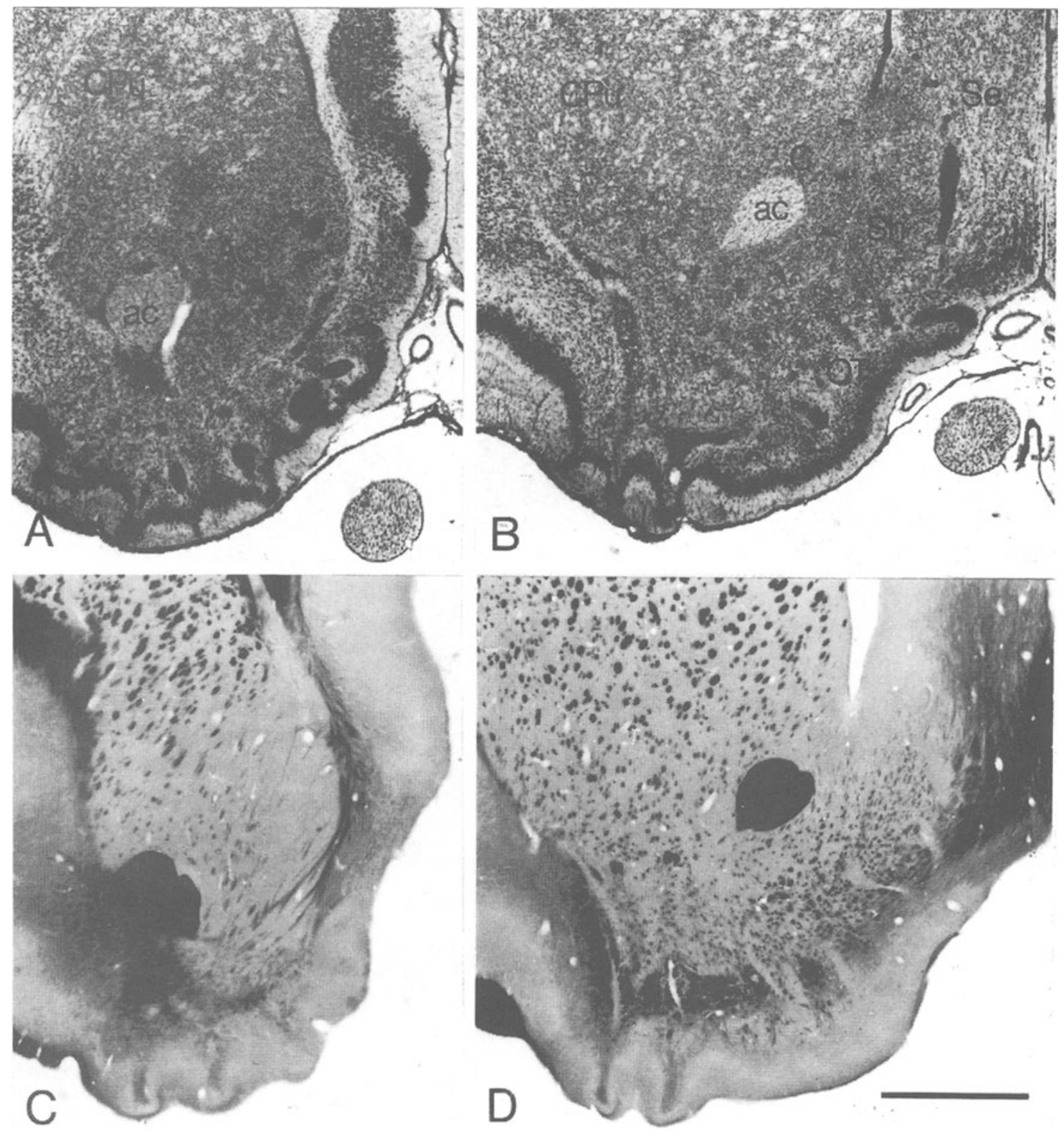

Figure 2. Photomicrographs of transverse sections through the Acb stained for Nissl substance (A, rostral; B, caudal) and myelinated fibers ( $C$, rostral; $D$, caudal). Note the existence of clusters of neurons (arrows in $A)$. In $B$, arrowheads mark the border between shell (Sh) and core (C); small dots indicate the border between the septal nuclei and the Acb. ac, anterior commissure; $C P u$, caudate-putamen complex; OT, olfactory tubercle; Se, septal nuclei. Bar in $D=1.0 \mathrm{~mm}$.

Cytoarchitectonically, the Acb seems at first glance as a rather homogeneous area (Figure 2A, 2B). Furthermore, the region of the Acb is largely devoid of myelinated fibers, in contrast to the caudate-putamen complex, which, in rats, is characterized by multiple bundles of internal capsule fibers (Figures 2C, 2D). The great majority of the neurons in the Acb are of the medium-sized, densely spiny type that form the output neurons of the nucleus. Only a small percentage (approximately $5 \%$ ) is larger, and these neurons form a heterogeneous popula- tion of interneurons (Meredith, Pennartz, \& Groenewegen, 1993). However, a more detailed study of the cytoarchitecture shows that cells are not equally dispersed over the nucleus; they form clusters of more densely packed cells in certain parts of the nucleus (Figure 2A, 2B; Chronister, Sikes, Trow, \& DeFrance, 1981; Herkenham et al., 1984; Voorn et al., 1989; for a review on the human ventral striatum, see Heimer et al., in press). It is of interest to note that the cellular density is in general lower in the shell than in the core and that the shell-core 
boundary, at least in the caudomedial part of the Acb, is marked by distinct cell clusters (Jongen-Rêlo, Groenewegen, \& Voorn, 1993; Jongen-Rêlo et al., 1994; Meredith et al., 1993; Wright \& Groenewegen, 1995, 1996). Therefore, in well-stained Nissl material, it is in principle possible to distinguish between shell and core.

\section{The Topographical Relationships of Hippocampal and Amygdaloid Afferents to the Acb}

The projections of the hippocampal formation and the basal amygdaloid complex have been mapped in considerable detail in previous antrograde and retrograde neuroanatomical tracing studies (rat, Brog et al., 1993; Groenewegen et al., 1987; Kelley \& Domesick, 1982; Kelley et al., 1982; Kita \& Kitai, 1990; McDonald, 1991; Shinonaga, Takada, \& Mizuno, 1994; Wright et al., 1996; cat, Groenewegen et al., 1980; Groenewegen et al., 1982; Ragsdale \& Graybiel, 1988; monkey, Russchen, Bakst, Amaral, \& Price, 1985). Both afferent systems exhibit a clear topographical relationship in their projections to the Acb. For the projections from the hippocampal formation, in particular from the subiculum, the topography is such that the ventral subiculum projects most densely to the caudomedial part of the Acb, whereas progressively more dorsal parts of the subiculum send fibers to successively more lateral and rostral parts of the Acb (Brog et al., 1993; Groenewegen et al., 1987). The topography in the projections from the basal amygdaloid complex to the Acb is rather complex, but a general trend is that caudal parts of the amygdala project medially in the Acb, whereas more rostral parts of the amygdala send fibers to more lateral parts of the nucleus (McDonald, 1991; Shinonaga et al., 1994; Wright et al., 1996). Since the ventral and dorsal hippocampus, as well as the caudal and rostral parts of the basal amygdaloid complex, may subserve different functional roles, it is of significant interest to identify precisely their areas of termination within the Acb and to determine whether they remain segregated or converge. In the following sections, the topographical arrangement of the hippocampal and amygdaloid projections to the Acb is described using a series of four transverse standard sections of the Acb (drawings based on the CaBstained sections shown in Figure 1) onto which the labeling resulting from anterograde tracer injections in different
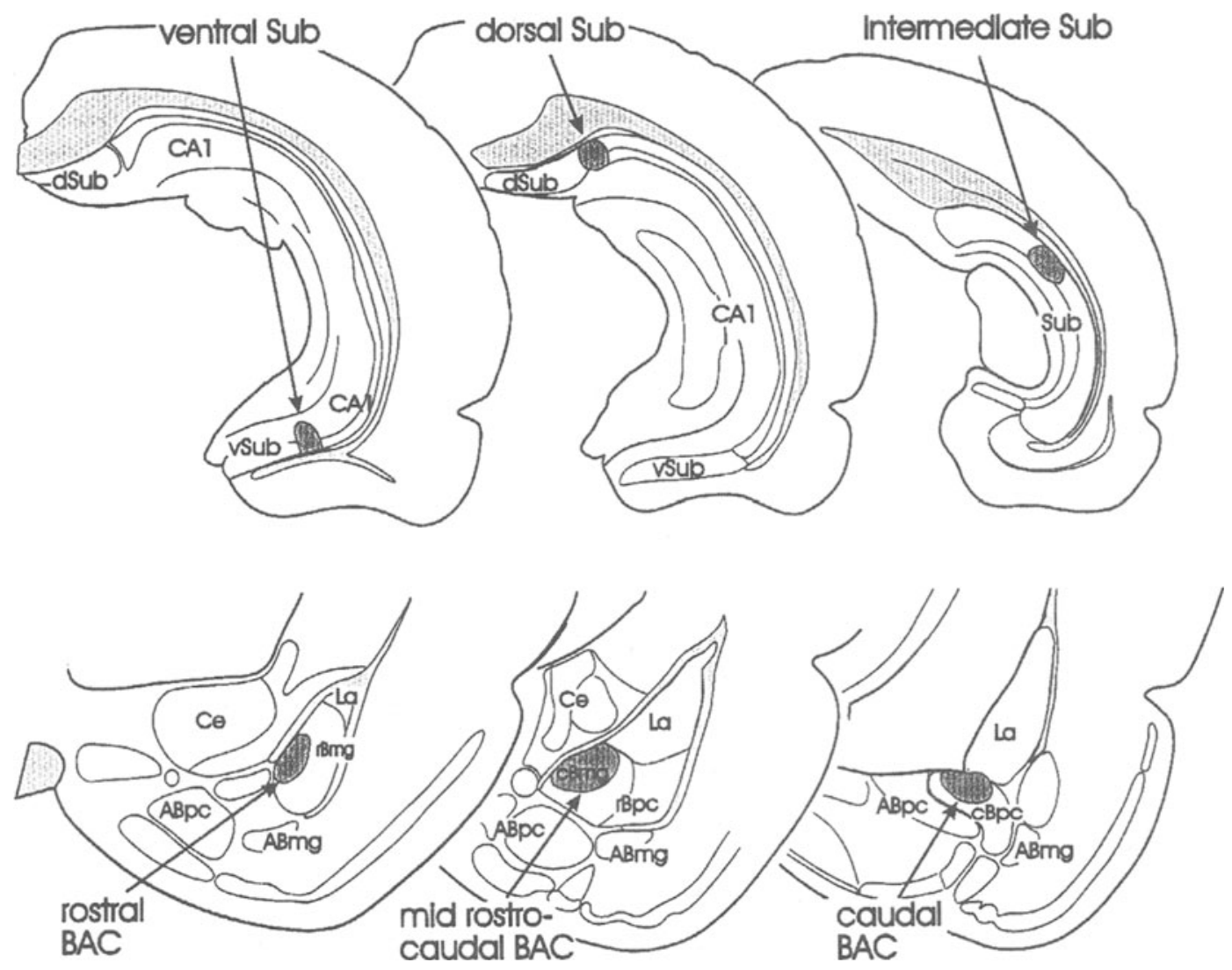

Figure 3. Schematic representation of the location of the injection sites of anterograde tracers in the subiculum of the hippocampal formation (Sub) and the basal amygdaloid complex (BAC). The resultant anterograde labeling in the Acb is shown in Figure 4. ABmg, magnocellular accessory basal nucleus; $\mathbf{A B p c}$, parvicellular $\mathbf{A B}$; $\mathbf{c B p c}, \mathbf{c a u}-$ dal part of the parvicellular basal nucleus; Ce, central nucleus; $\mathrm{CBmg}$, caudal part of the magnocellular basal nucleus; dSub, dorsal subiculum; La, lateral nucleus; rBmg, rostral part of the Bmg; rBpe, rostral part of the Bpc; vSub, ventral subiculum. 
parts of the hippocampal formation and the amygdala, placed in different animals, is converted. The data presented here are primarily based on the results of experiments reported by Groenewegen et al. (1987) for the projections from the hippocampal formation and by Wright et al. (1996) for those from the basal amygdaloid complex. The reader is referred to these papers for details of the experimental procedures.

Topography of subicular projections to the Acb. The topographical arrangement of the projections from different parts of the subiculum along the septotemporal axis of the hippocampal formation is summarized in Figures 3 and $4 \mathrm{~A} / \mathrm{I}-\mathrm{IV}$. Thus, the distribution of fibers from three injection sites of an anterograde tracer (either Phaseolus vulgaris-leucoagglutinin [PHA-L] or biotinylated dextranamide [BDA]) in the subiculum (Figure 3) is shown at four different rostrocaudal levels of the Acb. Ventral subicular fibers (blue in Figure 4) ascend through the precommissural fornix via the lateral part of the septum to massively enter the caudomedial part of the Acb (Figure 4A/IV). The ventral subicular fibers are predominantly directed toward the medial shell, but they extend also into the medial part of the core of the Acb and the extreme ventromedial part of the caudate-putamen complex (Figure 4A/II-IV). Whereas in the caudal $A c b$ the ventral subicular fibers occupy almost the entire medial shell, at more rostral levels that termination area becomes more and more restricted to the dorsomedial part of the shell and adjacent core (Figure 4A/I, II).

Fibers originating from an injection in the intermediate septotemporal part of the subiculum (Figure 3 ) ascend through more medial parts of the septum than those from the ventral subiculum. The intermediate subicular fibers (red in Figure 4A) terminate primarily in the rostral half of the Acb in the ventromedial and rostral shell. Fewer projections are found in the ventromedial shell in the caudal Acb, as well as in the ventral parts of the core (Figure 4A/I-III).

The dorsal part of the subiculum (Figure 3 ) sends fibers (green in Figure 4A) via the dorsal fornix (Groenewegen et al., 1987) through the most medial part of the septum to rostrolateral and rostroventral parts of the Acb, in particular its shell compartment (Figure 4A/I, II). Only a few fibers are present in the lateral shell in the caudal half of the Acb. In the rostral Acb, fibers from the dorsal subiculum extend into the lateral core (Figure 4A/I, II).

Topography of basal amygdaloid projections to the Acb. Amygdaloid fibers enter the Acb either from a caudal direction (from caudal parts of the basal amygdaloid complex) via the stria terminalis and its bed nucleus or from a lateral direction (from rostral parts of the basal amygdaloid complex) via the external capsule (see also Wright et al., 1996).

The caudal part of the parvicellular basal amygdaloid nucleus (Bpc; Figure 3) sends fibers (blue in Figure 4B) primarily to the caudomedial part of the shell of the Acb as well as to the adjacent medial part of the core (Figure $4 \mathrm{~B} / \mathrm{II}, \mathrm{IV}$ ). In the rostral half of the Acb (Figure 4B/
I, II), termination of fibers from the parvicellular basal amygdaloid nucleus is very scarce and restricted to the extreme dorsomedial corner of the shell.

Intermediate rostrocaudal levels of the basal amygdaloid complex project more laterally and ventrally in the Acb. The red label in Figure 4B represents the distribution of fibers and terminals in the Acb following an injection in the caudal part of the magnocellular basal nucleus (Bmg; Figure 3). These projections are mostly directed toward ventromedial parts of the shell throughout the rostrocaudal extent of the nucleus (Figure 4B/ I-IV). Additional projections are present in the patches of the medial core, as well as in the medial part of the olfactory tubercle. Injections at the same intermediate rostrocaudal levels of the amygdala, but located in the accessory basal nucleus, result in a distribution of fibers and terminals in the same parts of the shell and core as described above for the parvicellular basal amygdaloid nucleus. In the Acb core, however, the projections from the accessory basal nucleus are directed toward the matrix compartment as opposed to the parvicellular basal amygdaloid fibers, which target the patches (see Wright et al., 1996).

The rostral part of the basal amygdaloid complex, represented by the rostral part of the magnocellular basal nucleus (Figure 3), sends projections (green in Figure 4B) to the lateral shell of the Acb, the patches of the lateral core, and the lateral part of the olfactory tubercle (Figure 4B/ I-IV). In the lateral part of the core, fibers and terminals are also present in the matrix compartment, although to a lesser extent than in the patches (Figure 4B/II-IV).

Hippocampal-amygdaloid relationships. As can be deduced from a comparison of Figures $4 A$ and $4 B$, the distribution of hippocampal inputs to the Acb is more restricted than that from the amygdala. Whereas the fibers from the basal amygdaloid complex reach virtually all parts of the shell and core of the Acb, hippocampal projections are restricted to the medial parts of both the shell and the core in the caudal half of the Acb. In the rostral half of the Acb, hippocampal fibers, in addition, extend into the lateral parts of the shell and, very restrictedly, the ventrolateral part of the core. The central and lateral parts of the core do not receive substantial numbers of direct hippocampal afferents. These observations, based on anterograde tracing, are in good agreement with the results of retrograde tracing experiments with small injections in different parts of the Acb (Brog et al., 1993; Phillipson \& Griffiths, 1985). The latter studies further show that hippocampal fibers to the Acb arise not only from the subiculum but also from neurons in CA 1, adjacent to the subiculum (Brog et al., 1993; Groenewegen et al., 1987).

Convergence of hippocampal and amygdaloid inputs occurs primarily in the medial shell and core, as well as in more lateral parts of both Acb subdivisions in the rostral half of the nucleus. However, as noted, inputs from specific parts of the hippocampus converge with inputs from particular subnuclei (or parts thereof) of the basal amygdaloid complex. Thus, the ventral hippocampus and 

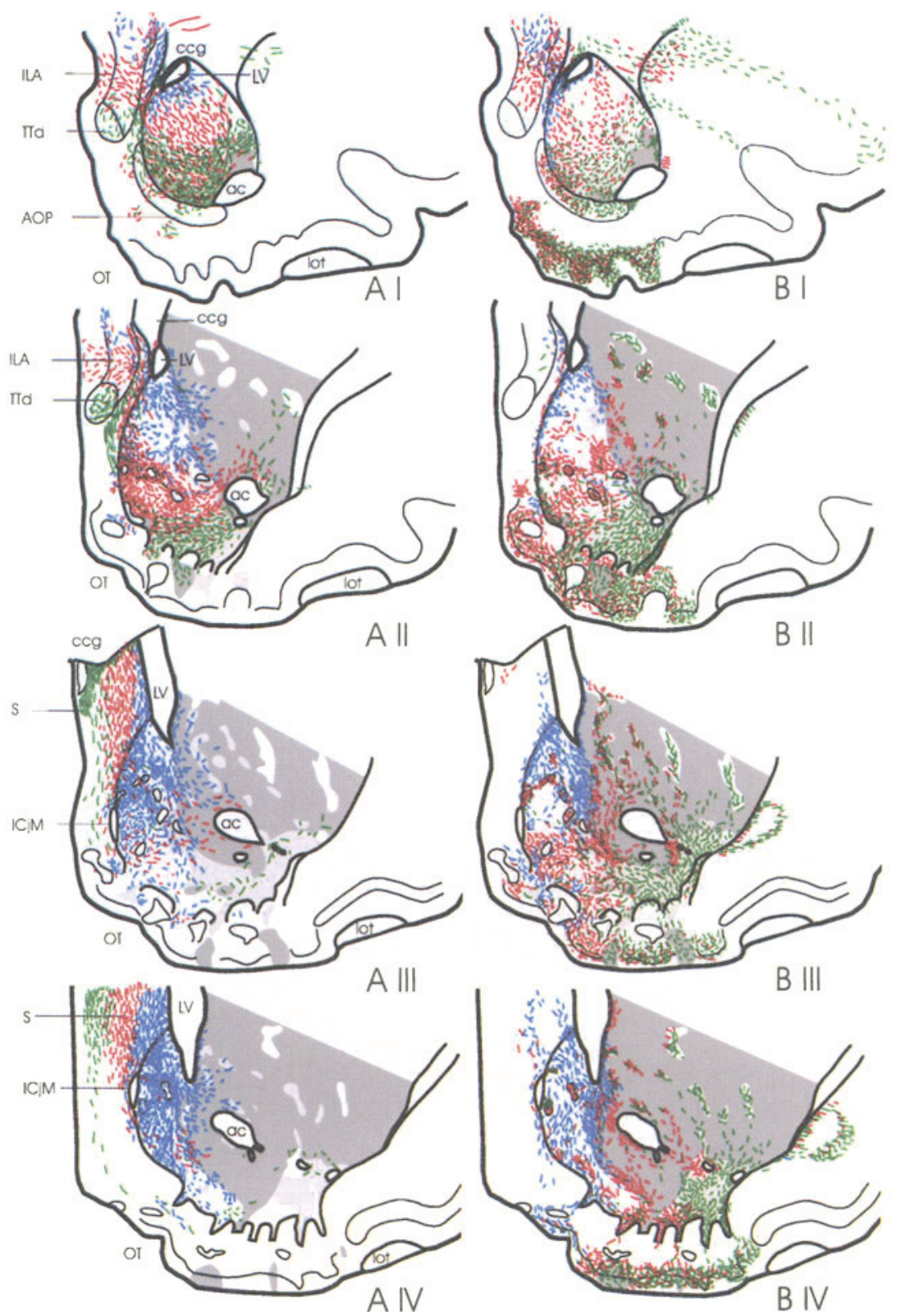

Figure 4. Schematic representation of the distribution of the anterograde labeling in the Acb following injections in different parts of the hippocampal formation (A/I-IV) and the basal amygdaloid complex (B/L-IV). The drawings of the Acb are based on the sections stained for $\mathrm{CaB}$ shown in Figure 1. Fibers and terminals originating from the ventral subiculum (A/I-IV) and those from the caudal part of the parvicellular basal amygdaloid nucleus (B/I-IV) are represented in blue, those from the intermediate part of the subiculum (A/I-IV) and from the midrostrocaudal amygdala (B/I-IV) are shown in red, and the fibers and terminals from the dorsal subiculum (A/I-IV) and the rostral part of the magnocellular basal amygdaloid nucleus (B I-IV) are depicted in green. Note that the projections from the midrostrocaudal amygdala depicted here are derived from an injection site in the caudal part of the magnocellular basal nucleus ( $\mathrm{cBmg}$ ). This nucleus projects in the Acb core and the adjacent ventral part of the caudate-putamen complex to the so-called striatal patch compartment. Projections from the accessory basal nucleus, located at approximately the same rostrocaudal level in the amygdala, reach the same region of the shell and core of the Acb, but in the core target primarily the striatal matrix compartment (for details, see Wright, Beijer, \& Groenewegen, 1996). Note that the area of the Acb with converging hippocampal and amygdaloid projections includes the medial shell and core in the caudal half of the nucleus, and the ventral and lateral shell as well as the ventral core in the rostral half of the Acb. ac, anterior commissure; AOP, posterior part of the anterior olfactory nucleus; ccg, genu of the corpus callosum; ILA, infralimbic area; lot, lateral olfactory tract; LV, lateral ventricle; OT, olfactory tubercle; S, septum; TTd, tenia tecta. 
the caudal part of the basal amygdaloid complex converge largely in the caudomedial shell and, to a lesser degree in the medial core (Figure 4A/III, IV vs. 4B/III, IV). The intermediate septotemporal hippocampal and intermediate rostrocaudal amygdaloid regions converge in the ventromedial shell and the adjacent ventral core of the Acb, this pattern being most obvious in rostral parts of the nucleus (Figure 4A/I, II vs. 4B/I, II). The projections from the dorsal hippocampus converge with those from the rostral part of the basal amygdaloid complex (rostral Bmg) in the lateral shell and adjacent lateral core, and this occurs almost exclusively in the rostral Acb (Figure 4A/I, II vs. $4 \mathrm{~B} / \mathrm{I}, \mathrm{II})$. The results of double anterograde tracing studies demonstrate that areas of converging hippocampal and amygdaloid projections contain detailed patterns of overlap and segregation, indicating that within such areas, subregions with preferential hippocampal or amygdaloid inputs exist (Beijer \& Groenewegen, 1996; Beijer, Wright, Witter, Smeets, \& Groenewegen, unpublished observations).

\section{PHYSIOLOGICAL INTERACTIONS BETWEEN HIPPOCAMPAL AND AMYGDALOID INPUTS IN THE NUCLEUS ACCUMBENS}

\section{Electrophysiological Characteristics of Hippocampal and Amygdaloid Inputs in the Acb}

In view of the role of the Acb as a limbic-motor interface, it is important to determine how the hippocampal and amygdaloid inputs are physiologically characterized and to establish their possible interactions. The electrophysiological characteristics of the projections of the hippocampal formation and of the basal amygdaloid complex have been mapped in detail in rats (Boeijinga, Pennartz, \& Lopes da Silva, 1990; Calloway, Hakan, \& Henriksen, 1991; Finch, 1996; Hakan \& Henriksen 1987; O'Donnell \& Grace, 1995; Yang \& Mogenson, 1984, 1985; Yim \& Mogenson, 1982, 1986, 1989), but also in rabbits (DeFrance, Marchand, Stanley, Sikes, \& Chronister, 1980; DeFrance, Marchand, Sikes, Chronister, \& Hubbard, 1985) and cats (Lopes da Silva, Arnolds, \& Neijt, 1984). However, the interactions between these two inputs were analyzed in only a few studies.

One of the earliest electrophysiological studies in which the amygdaloid and hippocampal projections to the Acb were examined simultaneously was performed by DeFrance, Marchand, Stanley, Sikes, and Chronister (1980). These authors described convergence of these two inputs in nine cells in the dorsal part of the caudal $A c b$, but their precise localization in the nucleus is unknown. More recent studies have confirmed the convergence of amygdaloid and hippocampal inputs in the Acb but either without a clear localization of the target cells (O'Donnell \& Grace, 1995), or in only a very small number of neurons (Finch, 1996). Therefore, to provide a more comprehensive account of the interactions of the inputs arising from the hippocampal formation and the basal amygdaloid complex in the Acb, these projections were studied simultaneously in rats under halothane anaesthesia (Mulder, Gijsberti Hodenpijl, \& Lopes da Silva, 1998). The core of the data discussed in the following paragraphs is largely derived from this paper, in which the details of the experimental procedures are given.

The hippocampal formation projections to the Acb. Before the physiological interactions of the hippocampal and amygdaloid inputs to the Acb can be appreciated, the electrophysiological characteristics of both pathways need to be discussed separately. As was discussed in previous sections, the main projections of the hippocampal formation to the Acb arise from the subiculum and course through the fornix/fimbria fiber bundle (Fo/Fi). Electrical stimulation of these fibers results in a characteristic evoked field potential (EFP; Figure 5A) that consists of a number of components: an initial negativity with a maximum at $6 \mathrm{msec}$ followed by two shortlatency positive synaptic components peaking at about 10 and $22 \mathrm{msec}$ (P10 and P22) (Boeijinga, Mulder, Pennartz, Manshanden, \& Lopes da Silva, 1993; Mulder, Arts, \& Lopes da Silva, 1997). Whereas the first component is the result of a monosynaptic activation, the P22, of polysynaptic origin, arises from a loop involving intrahippocampal circuits (Boeijinga et al., 1993). The occurrence of action potentials always coincides with the rising phase or the peak of the positive components of the EFP (e.g., either the P10 or the P22). Accumbens neurons always respond with one single action potential upon a single stimulus, so no burst activity could be detected. This is in contrast to neuronal activation by glutamate iontophoresis, where bursts up to five action potentials could be elicited (Mulder, Zuiderwijk, \& Lopes da Silva, 1995). This reflects the existence of a strong inhibitory GABAergic feedforward inhibition, which was also found in Acb slice preparations (Pennartz \& Kitai, 1991). The EFPs throughout the entire medial Acb are of similar amplitude and latency with polarity changes only at the dorsal and ventral borders (DeFrance et al., 1985; Lopes da Silva et al., 1984; Mulder et al., 1997). This strongly suggests that the input from the hippocampal formation to the region of the Acb is restricted to this nucleus, which is in line with the anatomical data (see above). The localization of the Acb neurons activated by Fo/Fi stimulation clearly shows that the majority of these neurons are located in the medial shell and core regions (Figure 6). The lateral shell and the ventrolateral core are devoid of Fo/Fi driven units. This is in accordance with the termination patterns described on the basis of anatomical tracing studies (cf. Figure 4). The distribution of latencies of single units responding to $\mathrm{Fo} / \mathrm{Fi}$ stimulation (i.e., the shortest latencies in the caudomedial area of the Acb and an increase in latency in a rostral and ventrolateral direction; Mulder et al., 1998), is compatible with the anatomical observations that the $\mathrm{Fo} / \mathrm{Fi}$ fibers enter the Acb from a caudal dorsomedial position, fanning out in rostral and lateral directions (see also Groenewegen et al., 1987). However, no clear division between shell and core, in 

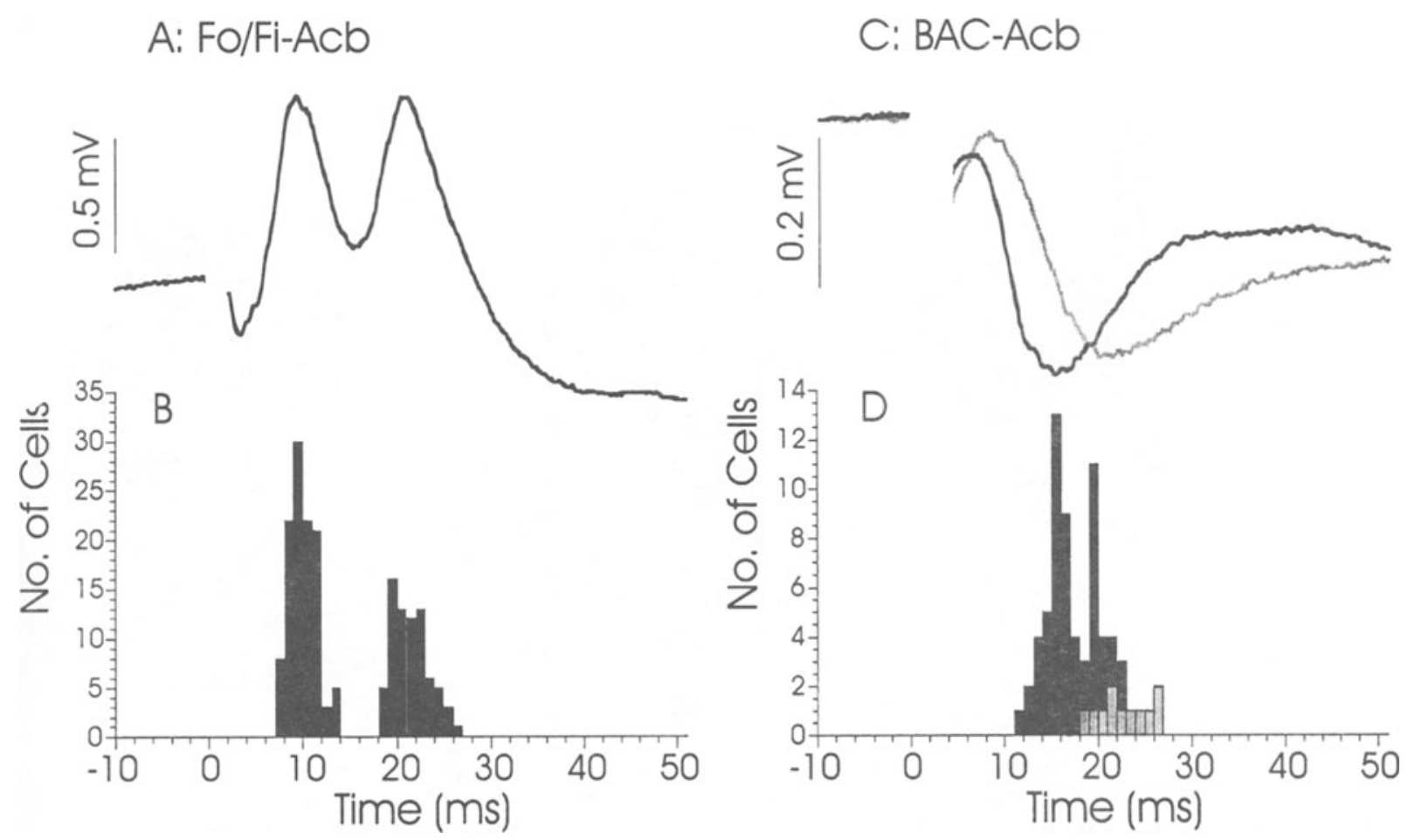

Figure 5. Evoked responses recorded in the Acb following Fo/Fi or amygdala (BAC) stimulation. Recording in the medial shell and medial core regions of the Acb resulted in EFPs with positive peak latencies of approximately 10 and 22 msec to Fo/Fi stimulation (trace in $A)$ and negative peak latencies of approximately $16 \mathrm{msec}$ to amygdala stimulation (C, black trace). In the ventrolateral shell and core regions, upon BAC stimulation, EFPs with longer latencies were recorded (C, gray trace). The distribution of the latencies of $A$ cb single units driven by Fo/Fi (B) and/or by amygdala (D) stimulation are given. Clearly visible are the two distinct latencies for the Fo/Fi driven neurons that correspond to the two peaks of the evoked field potential P10 and P22. The amygdala-driven units recorded in the medial shell and core of the Acb display latencies with peaks at 15 and $19 \mathrm{msec}$ (in black). Neurons displaying, on the average, longer latencies to amygdala stimulation were exclusively found in the ventrolateral parts of the Acb in both shell and core (in gray). BAC, basal amygdaloid complex.

any direction, can be made with respect to the latency of firing. Following these initial excitatory components, a long-latency positive deflection can be seen in the EFP that can last between 300 and $600 \mathrm{msec}$. Spontaneously active neurons in the Acb are inhibited during this period (Mulder et al., 1997). Stimulation of the ventral subiculum, basal amygdaloid complex, and lateral entorhinal cortex also leads to a short excitation followed by an inhibitory phase that can therefore be considered a common feature of all Acb excitatory inputs (Finch, Gigg, Tan, \& Kosoyan, 1995; Yang \& Mogenson, 1984; Yim \& Mogenson, 1982). The late inhibition is thought to be mediated by GABA-B receptors (Finch et al., 1995; Gigg, Tan, \& Finch, 1994).

The basal amygdaloid projections to the Acb. In contrast to the EFPs evoked by Fo/Fi activation, basal amygdaloid stimulation results in EFPs displaying a prominent negative field potential component (Figure 5C), on top of which the monosynaptic action potentials tend to ride (Mulder et al., 1998). In general, cells respond with a single spike upon one stimulus, although occasionally bursts of two or three action potentials were recorded, especially to higher stimulation intensities. In contrast to the neurons excited by Fo/Fi stimulation, the amygdaloid- driven neurons have the tendency to be more spontaneously active. Two separate populations of neurons responding to amygdaloid stimulation can be found in the Acb. In the medial part of the Acb, such neurons display relatively short latencies (around 15 and $19 \mathrm{msec}$ ), whereas in the ventrolateral $\mathrm{Acb}$, neurons with significantly longer latencies (up to $26 \mathrm{msec}$ ) were found (Figure 5C, Figure 6). These observations are in line with earlier reports, although no relationships between latencies and locations in the Acb have been reported previously (Finch, 1996; O'Donnell \& Grace, 1995; Yim \& Mogenson, 1982, 1986,1989 ). The distinctive difference in latency corresponds with the two routes by which the amygdaloid fibers course toward the Acb; that is, the caudal amygdala projects via the stria terminalis to the caudomedial Acb and the rostral amygdala via the external capsule to the lateral Acb (see Kita \& Kitai, 1990; Shinonaga et al., 1994; Wright et al., 1996). Since these pathways have different latencies, it is likely that they have different conduction times. In addition, the different peak latencies in the medial shell and core neurons may be due to the fact that the stria terminalis contains slower, as well as faster, conducting fibers (Fernandez de Molina \& Garcia-Sanchez, 1967). 


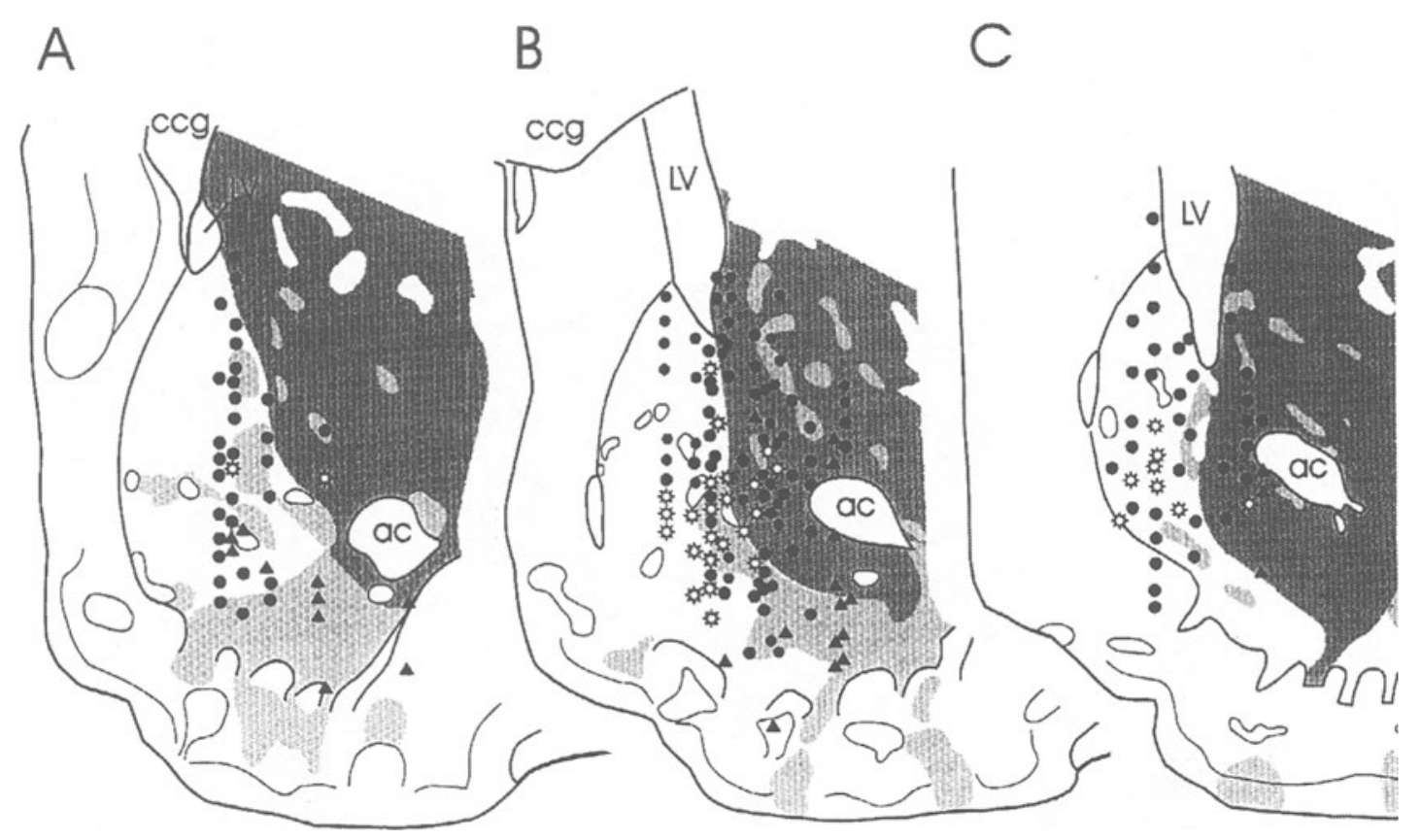

Figure 6. Distribution of single-unit activity within the Acb to Fo/Fi and amygdala stimulation. The drawings of the sections are based on three $\mathrm{CaB}$-stained sections shown in Figure 1. Single units driven by Fo/Fi stimulation are represented as filled circles and amygdala-driven single units are represented as triangles. Single units responding to both Fo/Fi and BLA stimulation are represented by open star shapes. Units driven by the Fo/Fi only were found in the dorsal shell and the ventromedial caudate putamen, whereas only amygdala-driven activity was recorded in the ventrolateral part of the Acb in both shell and core regions. Single units responding to both stimuli were recorded in the medial shell and medial core regions. (A) rostral section; (C) caudal section. From "Electrophysiology of the Hippocampal and Amygdaloid Projections to the Nucleus Accumbens of the Rat: Convergence, Segregation and Interaction of Inputs," by A. B. Mulder, M. Gijsberti Hodenpijl, and F. H. Lopes da Silva, 1998, Journal of Neuroscience, 18, p. 5098. Copyright 1998 by Society for Neuroscience. Adapted with permission.

As was seen for the Acb neurons responding to $\mathrm{Fo} / \mathrm{Fi}$, the projections from the basal amygdaloid complex to the Acb present shorter latencies in caudal areas and longer latencies in rostral areas of the nucleus. In line with the results of the anatomical tracing studies, a few single units ( $n=3$, latency $14 \pm 1 \mathrm{msec})$ in the olfactory tubercle were found to respond to amygdaloid stimulation. In the field potential evoked by amygdaloid stimulation, similar to that evoked by stimulation of Fo/Fi fibers, a long-latency positive deflection was found. Spontaneously active, amygdala-driven neurons in the Acb are inhibited during this period (Yim \& Mogenson, 1982).

Convergence and segregation of inputs within the nucleus accumbens. The convergence of inputs arising from the $\mathrm{Fo} / \mathrm{Fi}$ and from the basal amygdaloid complex was found mainly in the medial shell and medial core regions (Figure 6), but only rarely in the dorsomedial part of the shell of the Acb. No convergence was found in the ventrolateral shell and ventral core, or in the ventromedial part of the caudate-putamen complex. In general, this is in agreement with the results of other electrophysiological studies (DeFrance et al., 1985; Finch, 1996; O'Donnell $\&$ Grace, 1995). In the dorsomedial shell of the Acb and the ventromedial part of the caudate-putamen complex, only Fo/Fi driven cells were encountered. In contrast, in ventrolateral areas of the Acb, in both shell and core, exclusively single units driven by amygdaloid stimulation were found. No differences in response latencies between cells activated only by $\mathrm{Fo} / \mathrm{Fi}$ or cells that also received amygdaloid inputs were apparent. All amygdala-driven cells that presented convergence of inputs displayed short latencies, which were not different from those of cells solely activated by the amygdala, if recorded in the same accumbal region. The single units recorded in the ventrolateral areas, which showed no convergence, had long latencies. Close comparison of anatomical and electrophysiological results indicates that the units in the ventrolateral shell and the ventral core regions are all driven by afferents from the rostral part of the amygdala (Figure 4, depicted in green). Units that showed convergence of inputs received inputs from more midrostrocaudal and caudal parts of the basal amygdaloid complex and from ventral or intermediate parts of the subiculum (Figure 4).

The typical polarity of the EFP generated by excitatory postsynaptic potentials in the Acb (i.e., positive after $\mathrm{Fo} / \mathrm{Fi}$ stimulation and negative after amygdaloid stimulation) and the coincidence of unit firing with both these fields allows us to make some suggestions about the possible distribution of synaptic inputs. Throughout the entire 


\section{A: Fo/Fi stimulation}

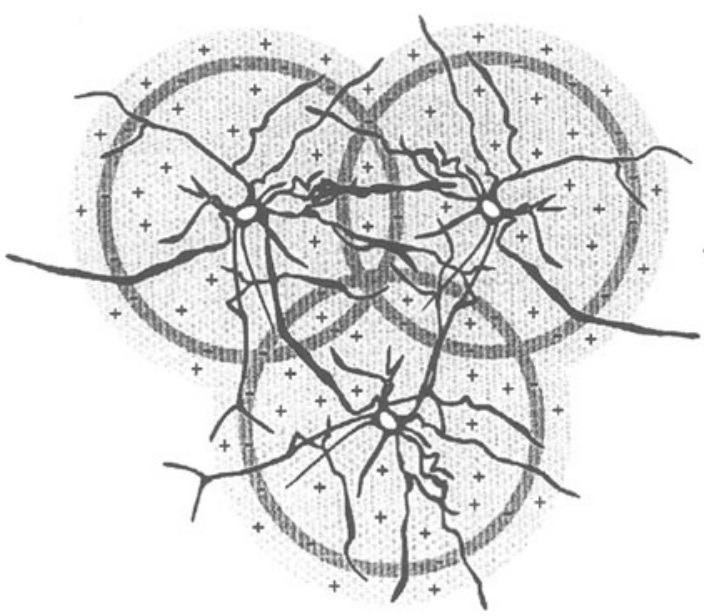

B: BAC stimulation

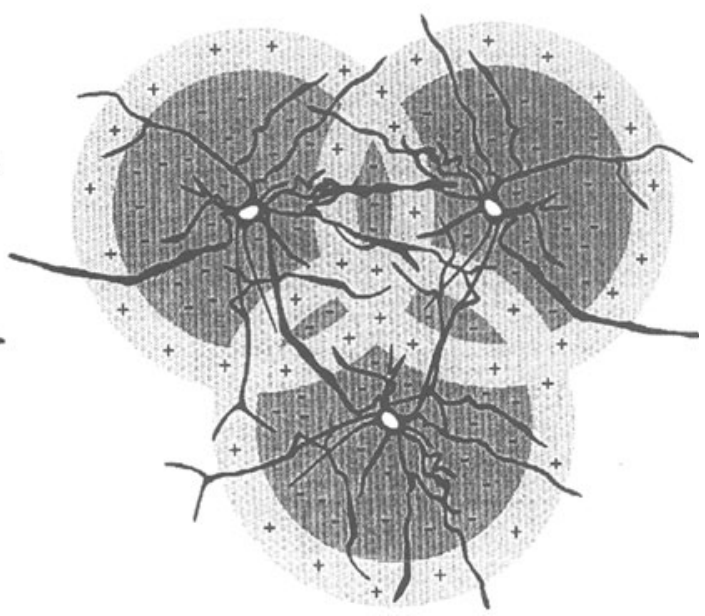

Figure 7. Model of terminal localization of hippocampal and basal amygdaloid input to the Acb, based on the polarity of the EFPs (see Figure 5) following stimulation of the respective inputs. In $A$ and $B$, the Acb is represented by three stellate cells, drawn after an accumbal medium-sized spiny neuron. The pronounced positive field potentials after Fo/Fi stimulation can be the result of hippocampal formation synapses being localized on the distal parts of the dendrites of the Acb neurons. In this way, after Fo/Fi stimulation (A), a distally localized current sink ( - , dark gray) is present that forms a ring around the Acb neuron. The rest of the proximal dendrites of the Acb neuron act as an extended current source (+, light gray), which is reflected in the strong positive evoked potentials throughout the nucleus. The negative field potential seen after amygdaloid stimulation (B) can be explained by BAC inputs terminating around the soma and along large areas of the proximal dendrites. This results in current sinks on large parts of the dendrites ( - , dark gray), surrounded by rings of sources $(+$, light gray). The sinks are dominant, and this is reflected in the negative-going deflection of the local field potential.

Acb, similar EFPs were recorded with polarity changes only at the dorsal and ventral borders (Lopes da Silva et al., 1984; Mulder et al., 1997). This is in line with the fact that the medium-sized spiny Acb neurons do not form welldefined layers, but have cell bodies occupying a central position surrounded by dendrites in all directions (Arts \& Groenewegen, 1992; DeFrance et al., 1985; Pennartz \& Kitai, 1991). Both hippocampal and amygdaloid terminals in the Acb have been shown to make asymmetrical synapses primarily on dendritic spines (Johnson, Aylward, Hussain, \& Totterdell, 1994; Kita \& Kitai, 1990; Meredith et al., 1993; Totterdell \& Smith, 1989). In general terms, extracellular fields are generated by a combination of sinks, at the site of active excitatory synaptic contacts, and sources at the remainder part of the somadendritic membrane (Lopes da Silva, 1996). Therefore, we hypothesize that the hippocampal afferents terminate on distal parts of the dendritic tree of Acb neurons, forming a distal sink that surrounds the cell body as a narrow ring, whereas the main part of the cell (i.e., the soma and the proximal dendrites) behaves like an extensive source (Figure 7). Because the neurons with all their dendritic arborizations overlap, the resultant field will be dominated by these sources. The finding of negative population spikes riding on the positive peak of the local field potential strengthens this interpretation. However, after stimulation of the amygdala, negative population spikes are found to ride local negative field potential components. Accordingly, we assume that amygdaloid excitatory inputs result in proximal current sinks, distributed around the soma and along large areas of the proximal dendrites (Figure 7). Thus, it may be hypothesized that the hippocampal inputs make synaptic contacts primarily with distal dendrites, whereas the amygdaloid synapses are predominantly located more proximally on the dendrites.

\section{Interactions Between Hippocampal and Amygdaloid Inputs in the Acb}

An examination of the interactions between both limbic inputs in the areas of convergence of the monosynaptically driven $\mathrm{Fo} / \mathrm{Fi}$ and amygdaloid activity in the Acb discloses striking effects, both on a short- and a longduration scale. The former was studied by measuring paired pulse interaction between inputs, whereas the latter was examined using long-term potentiation (LTP) protocols. Paired pulse facilitation (PPF) was readily found in the Acb in response to stimulation of the hippocampal inputs, as well as to that of the amygdaloid projections to the $\mathrm{Acb}$, when both stimuli were given to the same pathway (Boeijinga et al., 1990; Mulder et al., 1997; Mulder et al., 1998). This homosynaptic PPF is most likely modulated by a strong presynaptic facilitatory mechanism (Kuhnt \& Voronin, 1994) that appears to be able to mask the long-latency GABA-B receptor-mediated 
inhibitory component found in both pathways. However, when the excitability of the amygdaloid pathway to the Acb was tested in the 200 -msec period after stimulation of the Fo/Fi fibers, the firing probability was markedly lower than after a single amygdaloid stimulation. In contrast, testing Fo/Fi to Acb excitability just after amygdala stimulation resulted in a marked increase in firing probability of the Fo/Fi response relative to one single Fo/Fi stimulation. This facilitation, however, was less than in the case of paired $\mathrm{Fo} / \mathrm{Fi}$ stimulation. The mechanism of the facilitatory heterosynaptic effect of a conditioning amygdaloid input on the test hippocampal response may be explained by considering the suggested model of terminal location presented earlier (Figure 7). Amygdaloid inputs depolarize the proximal part of the soma-dendritic membrane of the medium-sized spiny neurons of the Acb that have a stellate configuration. Accordingly, the hippocampal inputs that follow an amygdaloid stimulus encounter the soma of the Acb neurons that are already in a depolarized state. This could account for a postsynaptic facilitation of this form of paired responses. The amygdala to Acb suppression, however, is not easily accounted for. In part, it can be explained by the recent results of Blaha, Yang, Floresco, Barr, and Phillips (1997). They showed that ventral subiculum stimulation results in prolonged dopamine efflux in the Acb. This increase, if specific for the pathway from the hippocampal formation to the Acb, could explain the attenuation of amygdala responses after Fo/Fi excitation. However, these phenomena have not been studied for the amygdaloid inputs into the Acb.

Apart from these short-term interactions, interactions of longer duration can also be found between the two pathways. As noted, tetanization of the Fo/Fi resulted in decremental LTP in the Acb with a duration of approximately 60 min (Boeijinga et al., 1993; Mulder et al., 1997). Examined in the same rat, the nontetanized amygdalato-Acb pathway showed long-term depression (LTD) for the entire duration of the Fo/Fi-induced LTP in the Acb (Mulder et al., 1998). This heterosynaptic depression may be due to the fact that potentiation of the population of cells driven by Fo/Fi may cause a potentiation of GABAergic inhibition in surrounding cells. Indeed, we found that this form of LTP is accompanied by strong GABAergic feedforward inhibition in this neuronal population (Mulder, Gijsberti Hodenpijl, \& Lopes da Silva, 1995). Strikingly, the time period of dopamine efflux in the Acb after multiple ventral subiculum stimulations (Blaha et al., 1997 ) is similar to the duration of the LTP in the Fo/Fi pathway and the LTD in the amygdala to Acb pathway. This indicates that dopamine may also play a role in these phenomena. However, it cannot be ruled out that the heterosynaptic LTD results from a postsynaptic mechanism (Abraham \& Goddard, 1983) that may depress the activity of synapses of a separate input lying in close proximity to the tetanized one. In summary, strong similarities exist in the physiological responses of Acb neurons to hippocampal and amygdaloid stimulation. In the medial shell and core region of the Acb only, integration of these inputs is apparent. Here, strong interactions are shown to exist between the pathways from the hippocampal formation and the basal amygdaloid complex. Although we are just at the beginning of unraveling the underlying mechanisms, it may well be that GABAergic and dopaminergic receptors play leading roles in these phenomena.

\section{MECHANISMS OF SYNAPTIC TRANSMISSION AND PLASTICITY IN AMYGDALOID AND HIPPOCAMPAL INPUTS TO ACCUMBENS}

The hippocampal input to the Acb has been more extensively studied in in vitro slice preparations than the amygdaloid input. Intracellular recordings from Acb neurons in slices have revealed a predominant EPSP-IPSP sequence evoked by electrical stimulation of $\mathrm{Fo} / \mathrm{Fi}$ in a parasagittal slice preparation (Pennartz \& Kitai, 1991; cf. Chang \& Kitai, 1986). The EPSP was shown to be mediated primarily by AMPA receptors and the IPSP by $\mathrm{GABA}_{\mathrm{A}}$ receptors. The glutamatergic excitation evoked by stimulation of hippocampal afferents is mediated via monosynaptic contacts on medium-sized spiny neurons, whereas GABAergic inhibition is mediated via a disynaptic pathway (feedforward inhibition; Pennartz \& Kitai, 1991). At present, the most likely candidate mechanism underlying this feedforward inhibition is a glutamatergic excitation by hippocampal output of GABAergic interneurons in the Acb, which subsequently inhibit mediumsized spiny neurons (see Cowan, Wilson, Emson, \& Heizmann, 1990; Kita, Kosaka, \& Heizmann, 1990). This GABAergic input not only delimits the duration of effective AMPA receptor-mediated excitation, but also keeps NMDA receptor activity depressed (Pennartz, Boeijinga, Kitai, \& Lopes da Silva, 1991). O'Donnell and Grace (1995) confirmed direct excitation of accumbens neurons by hippocampal input in vivo and also showed hippocampal inputs to regulate an electrophysiological bistability in medium-sized spiny neurons, referred to as the alternate occurrence of "up" and "down" states in membrane potential (see also C. J. Wilson \& Kawaguchi, 1996).

In anaesthetized or awake animals, the mean spontaneous firing rate of Acb neurons is relatively low as compared with that in other brain areas, which is likely to relate to the presence of a strong inward rectifier $\mathrm{K}+$ current in these cells, keeping them in a quiescent, hyperpolarized state until a barrage of excitatory input arrives (Pennartz et al., 1991; Pennartz et al., 1994; Uchimura, Cherubini, \& North, 1989). As noted, stimulation of hippocampal inputs to the Acb in vivo evokes a transient excitation or an excitation followed by inhibition in many cells. These response patterns are consistent with, and can also largely be explained, by the sequence of glutamatergic EPSPs and $\mathrm{GABA}_{\mathrm{A}}$ receptor-mediated IPSPs observed intracellularly in vitro.

Much less is known about the intracellular events underlying neuronal responses to amygdala input in Acb, al- 
though the basic pattern of responding seems to be similar. Yim and Mogenson (1988) recorded fast depolarizinghyperpolarizing sequences in vivo that resembled the EPSP-IPSP response pattern described earlier in terms of kinetics, thus making it likely that glutamate and GABA are also the main transmitters shaping fast information transmission from amygdala to Acb.

Intracellular mechanisms underlying synaptic plasticity as observed in EFPs, as described, have not yet been addressed for the hippocampal projection to the Acb, but have been examined for the pathway from the prelimbic/ infralimbic cortex to Acb (Kombian \& Malenka, 1994; Pennartz, Ameerun, \& Lopes da Silva, 1993). AMPA receptors mediate fast excitation of medium-sized spiny neurons in the latter projection, and GABAergic inhibition acts to attenuate NMDA receptor-mediated activity. In vitro, long- and short-term potentiation of the AMPA receptor component can be elicited by tetanic stimulation of prelimbic afferents, and induction is facilitated by GABA $_{A}$ receptor blockade. LTP induction was shown to be mediated by NMDA receptors (Pennartz et al., 1993), thus in principle endowing the system with a capacity for associative memory storage (Bliss \& Collingridge, 1993). Kombian and Malenka (1994) showed that the long-lasting enhancement of the AMPA component is accompanied by a decrement of the NMDA component, suggesting that intense afferent activity may not only alter the synaptic efficacy of limbic input to Acb, but also affect the ability of the synaptic interface to induce and sustain further changes in strength (metaplasticity). It is not yet clear to what extent these findings apply to hippocampal or amygdaloid inputs to Acb. However, the central role of NMDA receptors in inducing plasticity in the hippocampal projection has been confirmed by NMDA receptor applications in vivo by Feasey-Truger and ten Bruggencate (1994).

\section{FUNCTIONAL IMPLICATIONS}

The relatively large degree of convergence between amygdaloid and hippocampal inputs to single Acb neurons permits further thinking about integration and association of information coming from these two distinct sources. Evidence has grown to suggest that especially the dorsal hippocampus of the rat encodes spatial information (McNaughton et al., 1996; O'Keefe \& Dostrovsky, 1971; O'Keefe \& Nadel, 1978; M. A. Wilson \& McNaughton, 1993), in particular the allocentric position of the animal. Other studies on hippocampal function suggest a broader role, specifically, in establishing and storing relational configurations of objects and environmental features (Eichenbaum \& Cohen, 1988; Wiener, 1996). The amygdaloid complex, including its basal complex, is strongly involved in making associations between primary reinforcers and conditioned stimuli (Gaffan, Murray, \& Fabre-Thorpe, 1993; Killcross, Robbins, \& Everitt, 1997; Nishijo, Ono, \& Nishino, 1988; Rogan,
Stäubli, \& LeDoux, 1997). Thus, temporal coincidence of a particular environmental configuration with a primary reinforcer or reward-predicting stimulus may be hypothesized to result in enhanced activation of Acb neurons receiving the convergent information. If such converging, temporally coinciding input is sufficiently intense to induce long-lasting changes in synaptic gain at the level of the medium-sized spiny neuron, then associations between hippocampal and amygdaloid inputs can in principle be stored in this limbic-Acb synaptic interface. For instance, when a particular environment is consistently paired in time with a primary reinforcer that elicits approach behavior, associative potentiation of hippocampal inputs carrying contextual information may be hypothesized to occur. Thus, on a future occasion where the environment is presented without the primary reinforcer, the environment alone would be sufficient in triggering a behavioral approach. Associating these pieces of information obviously relates to conditioned place preference (see Everitt et al., 1991). In a similar way, hippocampal inputs may be associated with information about secondary reinforcers, and this associative principle by no means needs to be restricted to information derived from the hippocampus and amygdala. As a final remark, it should be emphasized that, although the cellular machinery for associative storage capacity is present in Acb, it is unknown whether long-term potentiation and NMDA receptors in Acb do indeed subserve this function. Furthermore, this scheme of reasoning does not offer a functional explanation of the depression of amygdala inputs upon potentiation of the hippocampal pathway, as described above.

\section{REFERENCES}

Abraham, W. C., \& Goddard, G. V. (1983). Asymmetric relationships between homosynaptic long-term potentiation and heterosynaptic long-term depression. Nature, 305, 717-719.

adolphs, R., Tranel, D., Damasio, H., \& Damasio, A. R. (1995). Fear and the human amygdala. Journal of Neuroscience, 15, 5879-5891.

AlvareZ, P., Zola-Morgan, S., \& SQuire, L. R. (1995). Damage to the hippocampal region produces long-lasting memory impairment in monkeys. Journal of Neuroscience, 15, 3796-3807.

ArTs, M. P. M., \& Groenewegen, H. J. (1992). Relationships of the dendritic arborations of ventral striatomesencephalic projection neurons with bounderies of striatal compartments. An in vitro intracellular labelling study in the rat. European Journal of Neuroscience, 4, 574-588.

Beijer, A. V. J., \& Groenewegen, H. J. (1996). Specific anatomical relationships between hippocampal and basal amygdaloid afferents and different populations of projection neurons in the nucleus accumbens of rats. Society for Neuroscience Abstracts, 22, 413.

Berendse, H. W., Groenewegen, H. J., \& Lohman, A. H. M. (1992) Compartmental distribution of ventral striatal neurons projecting to the mesencephalon in the rat. Journal of Neuroscience, 12, 2079-2103.

Blaha, C. D., Yang, C. R., Floresco, S. B., Barr, A. M., \& Phillips, A. G. (1997). Stimulation of the ventral subiculum of the hippocampus evokes glutamate receptor-mediated changes in dopamine efflux in the rat nucleus accumbens. European Journal of Neuroscience, 9, 902-911.

Bliss, T. V. P., \& Collingridge, G. L. (1993). A synaptic model of memory: Long-term potentiation in the hippocampus. Nature, 361, $31-39$. 
Boeijinga, P. H., Mulder, A. B., Pennartz, C. M. A., ManshanDEN, I., \& LOPES DA SILVA, F. H. (1993). Response of the nucleus accumbens following fornix/fimbria stimulation of the rat. Identification and long-term potentiation of mono- and polysynaptic pathways. Neuroscience, 53, 1049-1058.

Boeijinga, P. H., Pennartz, C. M. A., \& Lopes da Silva, F. H. (1990) Paired-pulse facilitation in the nucleus accumbens following stimulation of the subicular inputs in the rat. Neuroscience, 35, 301-311.

Brog, J. S., Salyapongse, A., Deutch, A. Y., \& Zahm, D. S. (1993) The patterns of afferent innervation of the core and shell of the "accumbens" part of the rat ventral striatum: Immunohistochemical detection of retrogradely transported fluoro-gold. Journal of Comparative Neurology, 338, 255-278.

CADOR, M., RoBbins, T. W., \& EVERITT, B. J. (1989). Involvement of the amygdala in stimulus-reward associations: Interactions with the ventral striatum. Neuroscience, 30, 77-86.

Calloway, C., HaKan, R. L., Henriksen, S. J. (1991). Distribution of amygdala input to the nucleus septi: An electrophysiological investigation. Journal of Neural Transmission, 83, 215-225.

Chang, H. T., \& KITAI, S. T. (1986). Intracellular recordings from rat nucleus accumbens neurons in vitro. Brain Research, 366, 392-396.

Chronister, R. B., Sikes, R. W., Trow, T. W., \& DeFrance, J. F. (1981). The organization of the nucleus accumbens. In R. B. Chronister \& J. F. DeFrance (Eds.), The neurobiology of the nucleus accumbens (pp. 97-146). Brunswick, ME: Haer Institute for Physiological Research

Cowan, R. L., Wilson, C. J., Emson, P. C., \& Heizmann, C. W. (1990). Parvalbumin-containing GABAergic interneurons in the rat neostriatum. Journal of Comparative Neurology, 302, 197-205.

DAviEs, M. (1992). The role of the amygdala in conditioned fear. In J. P. Aggleton (Ed.), The amygdala: Neurobiological aspects of emotion, memory and mental dysfunction (pp. 255-305). New York: Wiley.

DeFrance, J. F., Marchand, J. F., Sikes, R. W., Chronister, R. B., \& HUBBaRD, J. I. (1985). Characterization of fimbria input to nucleus accumbens. Journal of Neurophysiology, 54, 1553-1567.

DeFrance, J. F., Marchand, J., Stanley, J. C., Sikes, R. W., \& ChroNISTER, R. B. (1980). Convergence of excitatory amygdaloid and hippocampal input in the nucleus accumbens septi. Brain Research, 185, 183-186.

Deutch, A. Y., \& CAMERon, D. S. (1992). Pharmacological characterization of dopamine systems in the nucleus accumbens core and shell. Neuroscience, 46, 49-56.

Eichendaum, H., \& Cohen, N. J. (1988). Representation in the hippocampus: What do hippocampal neurons code? Trends in Neurosciences, 11, 244-248.

Everitt, B. J., Morris, K. A., O'Brien, A., \& Robbins, T. W. (1991). The basolateral amygdala-ventral striatal system and conditioned place preference: Further evidence of limbic-striatal interactions underlying reward-related processes. Neuroscience, 42, 1-18.

Feasey-Truger, K. J., \& TEN BruggenCate, G. (1994). The NMDA receptor antagonist CPP suppresses long-term potentiation in the rat hippocampal-accumbens pathway in vivo. European Journal of Neuroscience, 6, 1247-1254.

Fernandez de Molina, A., \& Garcia-Sanchez, J. L. (1967). The properties of the stria terminalis fibers. Physiology Behavior, 2, 225-227.

FinCH, D. M. (1996). Neurophysiology of converging synaptic inputs from rat prefrontal cortex, amygdala, midline thalamus, and hippocampal formation onto single neurons of the caudate/putamen and nucleus accumbens. Hippocampus, 6, 495-512

Finch, D. M., GigG, J., TAN, A. M., \& Kosoyan, O. P. (1995). Neurophysiology and neuropharmacology of projections from entorhinal cortex to striatum in the rat. Brain Research, 670, 233-247.

GafFan, D., Murray, E. A., \& Fabre-ThorPE, M. (1993). Interaction of the amygdala with the frontal lobe in reward memory. European Journal of Neuroscience, 5, 968-975.

GigG, J., TAN, A. M., \& FinCH, D. M. (1994). Glutamatergic hippocampal formation projections to prefrontal cortex in the rat are regulated by GABAergic inhibition and show convergence with glutamatergic projections from the limbic thalamus. Hippocampus, 4, 189-198.

Groenewegen, H. J., Becker, N. E. H. M., \& Lohman, A. H. M. (1980). Subcortical afferents to the nucleus accumbens septi in the cat, studied with retrograde axonal transport of horseradish peroxidase and bisbenzimid. Neuroscience, 5, 1903-1916.

Groenewegen, H. J., Berendse, H. W., Wolters, J. G., \& Lohman, A. H. M. (1990). The anatomical relationship of the prefrontal cortex with the striatopallidal system, the thalamus and the amygdala: Evidence for a parallel organization. In H. B. M. Uijlings, C. G. VanEden, J. P. C. DeBruin, M. A. Corner, \& M. P. G. Feenstra (Eds.), The prefrontal cortex: Its structure, function and pathology (Progress in Brain Research, Vol. 85, pp. 95-118). Amsterdam: Elsevier.

Groenewegen, H. J., Room, P., WitTer, M. P., \& Lohman, A. H. M. (1982). Cortical afferents of the nucleus accumbens in the cat: Studied with anterograde and retrograde transport techniques. Neuroscience, 7, 977-996.

Groenewegen, H. J., Vermeulen-Van der Zee, E., te KortSCHOT, A., \& WitTER, M. P. (1987). Organization of the projections from the subiculum to the ventral striatum in the rat: A study using anterograde transport of Phaseolus vulgaris-leucoagglutinin. Neuroscience, 23, 103-120.

Groenewegen, H. J., Wright, C. I., \& Beijer, A.V. J. (1996). The nucleus accumbens: Gateway for limbic structures to reach the motor system? In G. Holstege, R. Bandler, \& C. B. Saper (Eds.), The emotional motor system (Progress in Brain Research, Vol. 107, pp. 485511). Amsterdam: Elsevier.

HAKan, R. L., \& HENRIKSEN, S. J. (1987). Systemic opiate administration has heterogeneous effects on activity recorded from nucleus accumbens neurons in vivo. Neuroscience Letters, 83, 307-312.

Heimer, L., Alheid, G. F., De Olmos, J. S., Groenewegen, H. J., Haber, S. N., HaRlan, R. E., \& Zahm, D. S. (1997). The accumbens, beyond the core-shell dichotomy. Journal of Neuropsychiatry \& Clinical Neurosciences, 9, 354-381.

Heimer, L., de Olmos, J. S., Alheid, G. F., Pearson, J., SakaMOto, N., MARKSTEINER, J., \& SwITZER, III, R. C. (in press). The human basal ganglia, Part 2. In F. Bloom, A. Björklund, \& T. Hökfelt (Eds.), Handbook of chemical neuroanatomy (Vol. 15). Amsterdam: Elsevier.

HeImer, L., \& WiLSON, R. D. (1975). The subcortical projections of the allocortex: Similarities in the neural associations of the hippocampus, the piriform cortex, and the neocortex. In M. Santini (Ed.), Golg Centennial Symposium: Perspectives in Neurobiology (pp. 177-193). New York: Raven.

Heimer, L., Zahm, D. S., \& Alheid, G. F. (1995). Basal ganglia. In G. Paxinos (Ed.), The rat nervous system (2nd ed., pp. 579-628). Sydney: Academic Press.

Heimer, L., Zahm, D. S., Churchill, L., Kalivas, P. W., \& WohltMANN, C. (1991). Specificity in the projection patterns of the accumbal core and shell in the rat. Neuroscience, 41, 89-125.

Herkenham, M., Moon-Edley, S., \& Stuart, J. (1984). Cell clusters in the nucleus accumbens of the rat, and the mosaic relationship of opiate, acetylcholinesterase, and subcortical afferent terminations. Neuroscience, 11, 561-593.

Johnson, L. R., Aylward, R. L., Hussain, Z., \& Totterdell, S (1994). Input from the amygdala to the rat nucleus accumbens: Its relationship with tyrosine hydroxylase immunoreactivity and identified neurons. Neuroscience, 61, 851-865.

JONGEN-RÊLO, A., GRoENEWEGEN, H. J., \& VoORN, P. (1993). Evidence for a multicompartmental histochemical organization of the nucleus accumbens in the rat. Journal of Comparative Neurology, 337, 267 276.

JoNGEN-RÊLo, A., VoorN, P., \& Groenewegen, H. J. (1994). Immunohistochemical characterization of the shell and core territories of the nucleus accumbens in the rat. European Journal of Neuroscience, 6 , $1255-1264$

Kelley, A. E., \& Domesick, V. B. (1982). The distribution of the projection from the hippocampal formation to the nucleus accumbens in the rat: An anterograde and retrograde-horseradish peroxidase study Neuroscience, 7, 2321-2335.

Kelley, A. E., Domesick, V. B., \& NAUTA, W. J. H. (1982). The amygdalastriatal projection in the rat-An anatomical study by anterograde and retrograde methods. Neuroscience, 7, 615-630.

Kelley, A. E., Smith-Roe, S. L., \& Holahan, M. R. (1997). Responsereinforcement learning is dependent on $N$-methyl-D-aspartate recep- 
tor activation in the nucleus accumbens core. Proceedings of the $\mathrm{Na}$ tional Academy of Sciences, 94, 12174-12179.

KillCross, S., RobBiNS, T. W., \& EveritT, B. J. (1997). Different types of fear-conditioned behaviour mediated by separate nuclei within amygdala. Nature, 388, 377-380.

KitA, H., \& KitaI, S. T. (1990). Amygdaloid projections to the frontal cortex and striatum in the rat. Journal of Comparative Neurology, 298, 40-49.

Kita, H., Kosaka, T., \& Heizmann, C. W. (1990). Parvalbuminimmunoreactive neurons in the rat neostriatum: A light and electron microscopic study. Brain Research, 536, 1-15.

Kombian, S. B., \& MaLENKa, R. C. (1994). Simultaneous LTP of nonNMDA and LTD of NMDA-receptor mediated responses in the nucleus accumbens. Nature, 368, 242-246.

Коов, G. F. (1992). Drugs of abuse: Anatomy, pharmacology and function of reward pathways. Trends in Pharmacological Sciences, 13, 177-184.

KUHNT, U., \& VORONIN, L. L. (1994). Interaction between paired pulse facilitation and long-term potentiation in area CAl of guinea-pig hippocampal slices: Application of quantal analysis. Neuroscience, 62, 391-397.

LeDoux, J. E. (1993). Emotional memory systems in the brain. Behavioural Brain Research, 58, 69-79.

LOPES DA SILVA, F. H. (1996). The generation of electric and magnetic signals of the brain by local networks. In R. Gregor \& U. Windhorst (Eds.), Comprehensive human physiology (Vol. 1, pp. 509-531). Berlin: Springer-Verlag.

Lopes da Silva, F. H., ARnolds, D. E., \& NeiJT, H. C. (1984). A functional link between the limbic cortex and ventral striatum: Physiology of the subiculum-accumbens pathway. Experimental Brain Research, 55, 205-214.

MCDONALD, A. J. (1991). Topographic organization of amygdaloid projections to the caudate putamen, nucleus accumbens, and related striatal-like areas of the rat brain. Neuroscience, 44, 15-33.

McNaughton, B. L., Barnes, C. A., Gerrard, J. L., Gothard, K., Jung, M. W., KNIERIM, J. J., Kudrimoti, H., QIN, Y., SkagGs, W. E., SUSTER, M., \& WeAVER, K. L. (1996). Deciphering the hippocampal polyglot: The hippocampus as a path integration system. Journal of Experimental Biology, 199, 173-185.

Meredith, G. E., Pennartz, C. M. A., \& Groenewegen, H. J. (1993). The cellular framework for chemical signalling in the nucleus accumbens. In G. W. Arbuthnott \& P. C. Emson (Eds.), Chemical signalling in the basal ganglia (Progress in brain research, Vol. 99, pp. 3-24). Amsterdam: Elsevier.

Mogenson, G. J., Jones, D. L., \& Yim, C. Y. (1980). From motivation to action: Functional interface between the limbic system and the motor system. Progress in Psychobiology, 14, 60-97.

Mulder, A. B., ArTs, M. P. M., \& Lopes DA Silva, F. H. (1997). Shortand long-term plasticity of the hippocampus to nucleus accumbens and prefrontal cortex pathways in the rat, in vivo. European Journal of Neuroscience, 9, 1603-1611.

Mulder, A. B., Gijsberti Hodenpijl, M., \& Lopes da Silva, F. H. (1995). Electrophysiology of the hippocampal and basolateral amygdaloid inputs to the nucleus accumbens of the rat: Patterns of convergence and segregation. European Journal of Neuroscience, 8, 151.

Mulder, A. B., Gijsberti Hodenpijl, M., \& Lopes da Silva, F. H. (1998). Electrophysiology of the hippocampal and amygdaloid projections to the nucleus accumbens of the rat: Convergence, segregation and interaction of inputs. Journal of Neuroscience, 18, 5095-5102.

Mulder, A. B., ZuiderwiJk, M., \& Lopes da Silva, F. H. (1995). Enhancement of long-term potentiation in the nucleus accumbens by removal of GABAergic inhibition. Pflügers Archives, European Journal of Physiology, 430, R177.

Nauta, W. J. H., Smith, G. P., Faull, R. L., \& Domesick, V. B. (1978). Efferent connections and nigral afferents of the nucleus accumbens in the rat. Neuroscience, 3, 385-401

Newman, R., \& Winans, S. S. (1980). An experimental study of the ventral striatum of the golden hamster: I. Neuronal connections of the nucleus accumbens. Journal of Comparative Neurology, 191, 167192.

NishiJo, H., ONO, T., \& NishiNo, H. (1988). Single neuron responses in amygdala of alert monkey during complex sensory stimulation with affective significance. Journal of Neuroscience, 8, 3570-3583.
O'Donnell, P., \& Grace, A. A. (1995). Synaptic interactions among excitatory afferents to nucleus accumbens neurons: Hippocampal gating of prefrontal cortical input. Journal of Neuroscience, 15, 3622-3639.

O'KeEFE, J., \& Dostrovsky, J. (1971). The hippocampus as a spatial map. Preliminary evidence from unit activity in the freely-moving rat. Brain Research, 34, 171-175.

O'KeEFE, J., \& NADEL, L. (1978). The hippocampus as a cognitive map. Oxford: Oxford University Press, Clarendon Press.

Parkinson, J. A., Olmstead, M. C., Burns, L. H., Robbins, T. W., \& EveritT, B. J. (1999). Dissociation in effects of lesions of the nucleus accumbens core and shell on appetitive Pavlovian approach behavior and the potentiation of conditioned reinforcement and locomotor activity by $d$-amphetamine. Journal of Neuroscience, 19 , 2401-2411.

Pennartz, C. M. A., Ameerun, R. F., \& Lopes da Silva, F. H. (1993). Synaptic plasticity in an in vitro slice preparation of the rat nucleus accumbens. European Journal of Neuroscience, 5, 107-117.

Pennartz, C. M. A., Boeijinga, P. H., Kitai, S. T., \& Lopes da Silva, F. H. (1991). Contribution of NMDA receptors to postsynaptic potentials and paired-pulse facilitation in identified neurons of the rat nucleus accumbens in vitro. Experimental Brain Research, 86, 190-198.

Pennartz, C. M. A., Groenewegen, H. J., \& Lopes da Silva, F. H. (1994). The nucleus accumbens as a complex of functionally distinct neuronal ensembles: An integration of behavioural, electrophysiological and anatomic data. Progress in Neurobiology, 42, 719-761.

Pennartz, C. M. A., \& Kitai, S. T. (1991). Hippocampal inputs to identified neurons in an in vitro slice preparation of the rat nucleus accumbens: Evidence for feed-forward inhibition. Journal of Neuroscience, 11, 2838-2847.

Phillipson, O. T., \& Griffiths, A. C. (1985). The topographic order of inputs to the nucleus accumbens in the rat. Neuroscience, 16, 275-296.

RaGSDALE, C. W., \& GraybieL, A. M. (1988). Fibers from the basolateral nucleus of the amygdala selectively innervate striosomes in the caudate nucleus of the cat. Journal of Comparative Neurology, 269, 506-522.

RobBins, T. W., \& EveritT, B. J. (1996). Neurobehavioural mechanisms of reward and motivation. Current Opinion in Neurobiology, 6, 228-236.

Rogan, M., StäUbli, U. V., \& LeDoux , J. E. (1997). Fear conditioning induces associative long-term potentiation in the amygdala. $\mathrm{Na}$ ture, 390, 604-607.

Russchen, F. T., Bakst, I., Amaral, D. G., \& Price, J. L. (1985). The amygdalostriatal projections in the monkey. An anterograde tracing study. Brain Research, 329, 241-257.

SCHEel-Krüger, J., \& Willner, P. (1991). The mesolimbic system Principles of operation. In P. Willner \& J. Scheel-Krüger (Eds.), The mesolimbic dopamine system: From motivation to action (pp. 559597). Chichester, U.K.: Wiley.

Shinonaga, Y., TAKada, M., \& Mizuno, N. (1994). Topographic organization of collateral projections from the basolateral amygdaloid nucleus to both the prefrontal cortex and the nucleus accumbens. Neuroscience, 58, 389-397

StratFord, T. R., \& Kelley, A. E. (1997). GABA in the nucleus accumbens shell participates in the central regulation of feeding behavior. Journal of Neuroscience, 17, 4434-4440.

Totterdell, S., \& Meredith, G. E. (1997). Topographical organization of projections from the entorhinal cortex to the striatum of the rat. Neuroscience, $\mathbf{7 8}, 715-729$.

TotTerdell, S., \& SMITH, A. D. (1989). Convergence of hippocampal and dopaminergic input onto identified neurons in the nucleus accumbens of the rat. Journal of Chemical Neuroanatomy, 2, 285-298.

Uchimura, N., Cherubini, E., \& North, R. A. (1989). Inward rectification in rat nucleus accumbens neurons. Journal of Neurophysiology, 62, 1280-1286.

Voorn, P., Gerfen, C. R., \& Groenewegen, H. J. (1989). Compartmental organization of the ventral striatum of the rat: Immunohistochemical distribution of enkephalin, substance $P$, dopamine and calcium binding protein. Journal of Comparative Neurology, 289, 189-201.

Weiner, I., Gal, G., Rawlins, J. N., \& Feldon, J. (1996). Differential involvement of the shell and core subterritories of the nucleus accumbens in latent inhibition and amphetamine-induced activity. $B e$ havioural Brain Research, 81, 123-134.

WIENER, S. I. (1996). Spatial, behavioral and sensory correlates of hippo- 
campal CA1 complex spike cell activity: Implications for information processing functions. Progress in Neurobiology, 49, 335-361.

WiLson, C. J., \& KaWAGUCHI, Y. (1996). The origins of two-state spontaneous membrane potential fluctuations of neostriatal spiny neurons. Journal of Neuroscience, 16, 2397-2410.

WiLson, M. A., \& MCNaUghton, B. L. (1993). Dynamics of the hippocampal ensemble code for space. Science, 261, 1055-1058.

Wright, C. I., BeiJer, A. V. J., \& GroeneWegen, H. J. (1996). Basal amygadaloid complex afferents to the rat nucleus accumbens are compartmentally organized. Journal of Neuroscience, 16, 1877-1893.

Wright, C. I., \& Groenewegen, H. J. (1995). Patterns of convergence and segregation in the medial nucleus accumbens of the rat: Relationships of prefrontal cortical, midline thalamic and basal amygdaloid afferents. Journal of Comparative Neurology, 361, 383-403.

Wright, C. I., \& Groenewegen, H. J. (1996). Patterns of overlap and segregation between insular cortical, intermediodorsal thalamic and basal amygdaloid afferents in the nucleus accumbens of the rat. Neuroscience, 73, 359-373.

YANG, C. R., \& MOGENSON, G. J. (1984). Electrophysiological responses of neurons in the nucleus accumbens to hippocampal stimulation and the attenuation of the excitatory responses by the mesolimbic dopaminergic system. Brain Research, 324, 69-84.

YANG, C. R., \& Mogenson, G. J. (1985). An electrophysiological study of the neural projections from the hippocampus to the ventral pallidum and the subpallidal areas by way of the nucleus accumbens. Neuroscience, 15, 1015-1024.

YIM, C. Y., \& Mogenson, G. J. (1982). Response of nucleus accumbens neurons to amygdala stimulation and its modification by dopamine. Brain Research, 239, 401-415.

YIM, C. Y., \& Mogenson, G. J. (1986). Mesolimbic dopamine projection modulates amygdala-evoked EPSP in nucleus accumbens neurons: An in vivo study. Brain Research, 369, 347-352.
Yim, C. Y., \& Mogenson, G. J. (1988). Neuromodulatory action of dopamine in the nucleus accumbens: An in vivo intracellular study. Neuroscience, 26, 403-415.

YIM, C. Y., \& Mogenson, G. J. (1989). Low doses of nucleus accumbens dopamine modulate amygdala suppression of spontaneous exploratory activity in rats. Brain Research, 477, 202-210.

Zàborszky, L., Alheid, G. F., Beinfeld, M. C., Eiden, L. E., HeIMER, L., \& PALKovits, M. (1985). Cholecystokinin innervation of the ventral striatum: A morphological and radioimmunological study. Neuroscience, 14, 427-453.

ZAHM, D. S., \& BROG, J. S. (1992). On the significance of subterritories in the "accumbens" part of the rat ventral striatum. Neuroscience, $\mathbf{5 0}$ $751-767$.

ZAHM, D. S., \& HEIMER, L. (1993). Specificity in the efferent projections of the nucleus accumbens in the rat: Comparison of the rostral pole projection patterns with those of the core and shell. Journal of Comparative Neurology, 327, 220-232.

Zola-Morgan, S., Squire, L. R., Alvarez-Royo, P., \& Clower, R. P. (1991). Independence of memory functions and emotional behaviour: Separate contributions of the hippocampal formation and the amygdala. Hippocampus, 1, 207-220.

Zola-Morgan, S., Squire, L. R., \& Amaral, D. G. (1986). Human amnesia and the medial temporal region: Enduring memory impairment following a bilateral lesion limited to field CA1 of the hippocampus. Journal of Neuroscience, 6, 2950-2967.

Zola-Morgan, S., SQuire, L. R., \& AMARAL, D. G. (1989). Lesions of the hippocampal formation but not lesions of the fornix or the mammillary nuclei produce long-lasting memory impairments in monkeys. Journal of Neuroscience, 9, 898-913.

(Manuscript received November 30, 1998; revision accepted for publication March 13, 1998.) 